\title{
COMMENTARY
}

\section{Re-evaluating high-frequency oscillation for ARDS: Would a targeted approach be successful?}

\author{
Ewan C Goligher and Niall D Ferguson* \\ See related research by Camporota et al., http://ccforum.com/content/17/2/R40
}

\begin{abstract}
High-frequency oscillatory ventilation (HFOV) seems ideal for lung protection in acute respiratory distress syndrome, but randomized trials have not shown a mortality reduction. The initial oxygenation response to HFOV appears to be associated with survival. Here, we discuss the mechanisms of oxygenation response to increases in airway pressure and the interpretation of the oxygenation response observed in the present study.
\end{abstract}

In this issue of Critical Care, Camporota and colleagues [1] report interesting observations on the relationship between the initial gas exchange response to highfrequency oscillatory ventilation (HFOV) and clinical outcomes. HFOV seems ideally suited to protecting the lung during mechanical ventilation in patients with acute respiratory distress syndrome (ARDS). By delivering very small tidal volumes and allowing higher mean airway pressures, HFOV can potentially minimize both volutrauma and atelectrauma [2]. However, the recently published OSCILLATE (OSCillation in ARDS Treated Early) [3] and OSCAR (High-Frequency OSCillation in ARDS) [4] trials - both of which postdate the article by Camporota and colleagues - found that HFOV failed to reduce mortality. In particular, OSCILLATE raised questions of potential harm from HFOV. In the face of these disappointing results, trialists and clinicians alike are left wondering how to reconcile theory to practice. A number of potential mechanisms for harm have been postulated, including (a) the deleterious effects of increased sedation, (b) hemodynamic embarrassment due to reduced right ventricular preload or increased

*Correspondence: n.ferguson@utoronto.ca

Interdepartmental Division of Critical Care Medicine, and Departments of Medicine and Physiology, University of Toronto, University Health Network and Mount Sinai Hospital, 600 University Avenue, Suite 18-206, Toronto, ON, Canada, M5G $1 \times 5$ right ventricular afterload, or (c) an increase in mechanical alveolar stress and strain within the baby lung [5]. Some combination of these mechanisms is likely to contribute to patient outcome during HFOV.

A critical factor influencing the importance of these various mechanisms may be the response of the individual patient to the application of high mean airway pressures. Imaging studies have demonstrated profound heterogeneity in the extent of alveolar recruitment in response to increases in airway pressure [6,7]. In patients with 'recruitable lung', higher airway pressures increase the size of the functional 'baby lung', reduce alveolar stress and strain, and may even reduce right ventricular afterload without significantly compromising right ventricular filling [8]. In patients lacking 'recruitable lung,' higher mean airway pressures achieve the opposite: worsened alveolar stress and strain and increased right ventricular afterload. Consequently, the potential for benefit or harm may depend critically on the degree of lung recruitment in response to increasing mean airway pressure.

Enter the interesting observations of Camporota and colleagues [1], who found that in patients with moderate or severe ARDS who were placed on HFOV by their attending physicians, the change in arterial partial pressure of oxygen/fraction of inspired oxygen $\left(\mathrm{P}_{\mathrm{a}} \mathrm{O}_{2} /\right.$ $\mathrm{F}_{\mathrm{i}} \mathrm{O}_{2}$ ) ratio 6 hours after HFOV initiation was associated with 30-day survival. Improvements in oxygenation were also associated with reductions in arterial partial pressure of carbon dioxide $\left(\mathrm{P}_{\mathrm{a}} \mathrm{CO}_{2}\right)$, particularly in patients with more severe respiratory failure, contradicting the widely held belief that HFOV inevitably worsens respiratory acidosis.

The oxygenation response to increased positive endexpiratory pressure (PEEP) is the product of a complex interplay between alveolar recruitment and cardiac output. Classic physiological studies by Dantzker and colleagues [9] and Lynch and colleagues [10] demonstrated that increased PEEP reduces intrapulmonary shunt both by re-opening collapsed lung units and by reducing cardiac output. In the latter case, non-ventilated lung units are preferentially affected by reduced blood 
flow, possibly because of the effects of hypoxic pulmonary vasoconstriction [11]. In the present study, Camporoto and colleagues reported that cardiac output was unchanged; thus, the short-term oxygenation response likely signifies lung recruitment.

The authors speculate that the gas exchange response may be a useful predictor of the utility of HFOV in the difficult-to-oxygenate patient and further propose that failure to demonstrate improved oxygenation after a 6-hour trial of HFOV should prompt a consideration of alternative rescue modalities such as extracorporeal life support. It is difficult, however, to do anything more than speculate on the basis of these data. First, it is difficult to be certain whether the association between early improvements in oxygenation and reduced mortality arises from the effects of HFOV-induced lung recruitment or simply represents the natural history of survivors (whose oxygenation will tend to improve with time) in contrast to non-survivors (whose oxygenation will tend to worsen with time). Second, even if the improvements in oxygenation were directly related to lung recruitment, it is impossible to discern whether oxygenation 'responders' have lower mortality than 'non-responders' because 'responders' have a less fatal form of ARDS or because they accrue greater benefit from HFOV. Finally, from these data in which all patients received HFOV, it is impossible to know whether increases in mean airway pressure on conventional ventilation would have been equally effective.

Such issues can be resolved only by a carefully designed randomized trial of an open-lung ventilation strategy that stratifies patients by oxygenation response prior to random assignment. In the meantime, in light of the available evidence, HFOV should usually be reserved for patients with refractory hypoxemia. When applying HFOV, clinicians should consider monitoring lung recruitment (by oxygenation response or other means available) and right ventricular function (by echocardiography or other hemodynamic monitoring) to ensure that this unique mode of ventilation is achieving appropriate physiological goals in the individual patient.
Abbreviations

$\mathrm{HFOV}$, high-frequency oscillatory ventilation; PEEP, positive end-expiratory pressure.

\section{Competing interests}

The authors declare that they have no competing interests.

Published: 19 April 2013

\section{References}

1. Camporota L, Sherry T, Smith J, Lei K, McLuckie A, Beale R: Physiological predictors of survival during high-frequency oscillatory ventilation in adults with acute respiratory distress syndrome. Crit Care 2013, 17:R40

2. Ferguson ND, Ferguson ND, Slutsky AS, Slutsky AS: Point:Counterpoint: High-frequency ventilation is/is not the optimal physiological approach to ventilate ARDS patients. J Appl Physiol 2008, 104:1230-1231.

3. Ferguson ND, Cook DJ, Guyatt GH, Mehta S, Hand L, Austin P, Zhou Q, Matté A, Walter SD, Lamontagne F, Granton JT, Arabi YM, Arroliga AC, Stewart TE, Slutsky AS, Meade MO, OSCILLATE Trial Investigators, Canadian Critical Care Trials Group: High-frequency oscillation in early acute respiratory distress syndrome. N Eng/ J Med 2013, 368:795-805.

4. Young D, Lamb SE, Shah S, MacKenzie I, Tunnicliffe W, Lall R, Rowan K, Cuthbertson BH, OSCAR Study Group: High-frequency oscillation for acute respiratory distress syndrome. N Engl J Med 2013, 368:806-813.

5. Malhotra A, Drazen JM: High-frequency oscillatory ventilation on shaky ground. N Engl J Med 2013, 368:863-865.

6. Puybasset L, Gusman P, Muller JC, Cluzel P, Coriat P, Rouby JJ: Regional distribution of gas and tissue in acute respiratory distress syndrome. III. Consequences for the effects of positive end-expiratory pressure. CT Scan ARDS Study Group. Adult Respiratory Distress Syndrome. Intensive Care Med 2000, 26:1215-1227.

7. Gattinoni L, Caironi P, Cressoni M, Chiumello D, Ranieri VM, Quintel M, Russo S, Patroniti N, Cornejo R, Bugedo G: Lung recruitment in patients with the acute respiratory distress syndrome. N Engl J Med 2006, 354:1775-1786.

8. Protti A, Cressoni M, Santini A, Langer T, Mietto C, Febres D, Chierichetti M, Coppola S, Conte G, Gatti S, Leopardi O, Masson S, Lombardi L, Lazzerini M, Rampoldi E, Cadringher P, Gattinoni L: Lung stress and strain during mechanical ventilation: Any safe threshold? Am J Respir Crit Care Med 2011, 183:1354-1362.

9. Dantzker DR, Brook CJ, Dehart P, Lynch JP, Weg JG: Ventilation-perfusion distributions in the adult respiratory distress syndrome. Am Rev Respir Dis 1979, 120:1039-1052.

10. Lynch JP, Mhyre JG, Dantzker DR: Influence of cardiac output on intrapulmonary shunt. J App/ Physiol 1979, 46:315-321.

11. Melot C: Contribution of multiple inert gas elimination technique to pulmonary medicine. 5 . Ventilation-perfusion relationships in acute respiratory failure. Thorax 1994, 49:1251-1258.

doi:10.1186/cc12602

Cite this article as: Goligher EC, Ferguson ND: Re-evaluating high-frequency oscillation for ARDS: Would a targeted approach be successful? Critical Care 2013, 17:133. 